\title{
OPTIMIZATION OF THE TRIBOLOGICAL CONTACT OF VALVE PLATE AND CYLINDER BLOCK WITHIN AXIAL PISTON MACHINES
}

\author{
Stefan Geffroy ${ }^{1 *}$, Niklas Bauer ${ }^{1}$, Tobias Mielke ${ }^{1}$, Stephan $_{\text {Wegner }}^{2}$, Stefan Gels ${ }^{3}$, \\ Hubertus Murrenhoff ${ }^{1}$, Katharina Schmitz ${ }^{1}$ \\ ${ }^{1}$ Institut for Fluid Power Drives and Systems, RWTH Aachen University, Campus-Boulevard 30, 52074 Aachen \\ ${ }^{2}$ Stackpole Powertrain International GmbH, Campus-Boulevard 30, 52074 Aachen \\ ${ }^{3} \mathrm{P} \& G$ Hydraulische Antriebstechnik GmbH, Nettestraße 39, 58762 Altena \\ * Corresponding author: Tel.: +49 24180 47741; E-mail address: Stefan.Geffroy@ifas.rwth-aachen.de
}

\begin{abstract}
In this paper, a simulation study is carried out for the development of concepts to optimize the tribological contact of valve plate and cylinder block in an axial piston machine in swash plate design. The valve plate/cylinder block contact is one of the three essential tribological contacts in axial piston machines. In a research project at the Institute for Fluid Power Drives and Systems (ifas), this contact is investigated by a specifically designed simulation tool. In addition, a test rig exists for the experimental investigation. With the results of simulation and experiment, it was shown before that the cylinder block is tilting to the high pressure side. Due to this movement, the gap height is not constant. In the area of minimum gap height, not only the fluid friction, but also the danger of solid body friction increases. Because of the higher friction losses in the area of minimum gap height, the temperature increase reduces the lifetime of the leaded coatings. In this paper, the results of the measurements as well as the simulation model are briefly summarized. It is followed by a simulation study of different possibilities to raise the gap height. Based on this pre-study, a first concept for the optimization of the tribological contact valve plate/cylinder block is presented and its applicability is discussed.
\end{abstract}

Keywords: Axial piston machine, simulation, unleaded coatings, temperatur hot-spot

\section{INTRODUCTION}

Axial piston machines are the most widely used type of hydraulic displacement machines and they are characterized by their high reliability and efficiency. Figure 1 shows an axial piston machine in swash plate design and its three essential tribological contacts piston/slipper, piston/bushing and valve plate/cylinder block [1]. This paper focuses on the contact valve plate/cylinder block. To prevent leakage from the high to the low pressure side through the gap between valve plate and cylinder block, it is necessary to exert a force which presses the cylinder block against the valve plate. If this force is too low, the gap height between the components increases, causing additional leakage and thus a decrease in volumetric efficiency. If the force is too high, the gap height decreases which leads to unlubricated contact of the surface causing additional wear and decrease in mechanical/hydraulic efficiency. Therefore, it is important to design the components and parameters in such a manner that a thin and evenly distributed oil film over the whole contact area is ensured.

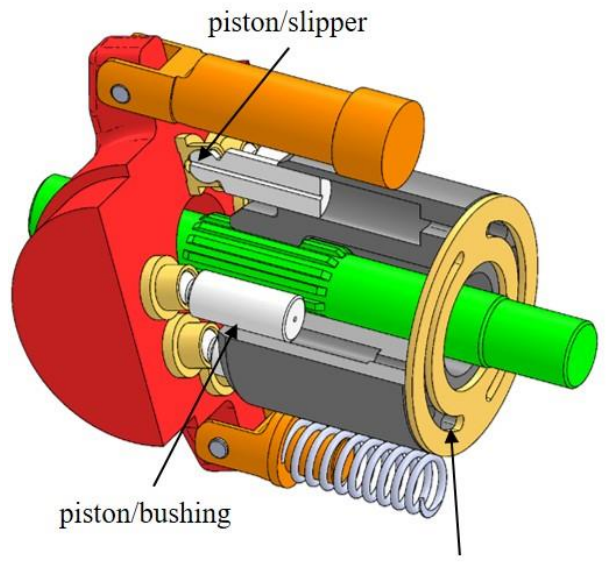

cylinder block/valve plate

Figure 1: Three essential tribological contacts in axial piston machines [2] 
Currently, a hard/soft pairing is used for the contact of cylinder block and valve plate. One option to realize such pairing is that the valve plate is made of steel while the surface of the cylinder block is coated with a brass alloy. A different option is that the valve plate is coated or made out of a brass alloy. This combination allows a bedding-in process, it is insensitive to manufacturing tolerances and generally leads to low wear and acceptable friction in case of direct contact of the surfaces. However, the use of leaded alloys causes disadvantages, including the occurrence of temperature-related cracks, fluid dependent wear and adhesion behaviour as well as material incompatibilities. In the EU, the use of the toxic heavy metal lead is strongly regulated [3].

Currently there are two approaches for the substitution of leaded alloys. First, an alternative unleaded material with similar properties can be developed, as shown in [4]. A second alternative is to realize a hard/hard pairing by the use of unleaded coatings or steel to steel. A simulation based pre-study as well as a first concept for the realization of these alternatives are presented in this paper.

\section{SIMULATION MODEL}

For a detailed investigation of the tribological contact valve plate/cylinder block a simulation model was built up at ifas. This simulation model is further development of a simulation model for the piston/bushing contact [5]. In [6], its development is described in detail and is only shortly presented in this paper.

The simulation tool was developed with the aim to compare several geometries at different operating points with acceptable computation time and sufficient result quality. To reach this goal, the simulation tool focuses on the following physical effects [5]:

- Hydrostatic and hydrodynamic pressure build up using the Reynolds equation

- Force and torque equilibrium on the cylinder block

- Squeeze film effect, viscous friction, microscopic part movement resulting from the first two points

- Macroscopic part movement calculated in an analytic way

- Simple contact and part deformation model
The finite volume method is used to solve the Reynolds equation. To calculate the gap height and the cylinder block movement, a linear system of equations coming from mass and momentum balances is set up and linked to the Reynolds equation. With the boundary conditions from the geometry and the known high and low pressure areas, the unknown variables and the number of equations are well balanced and the system can be solved numerically.

In the simulation model a simple method is used to calculate the solid friction. The gap height is compared to the reference gap height, which comes from the surface roughness. With it, the solid friction is calculated and takes place as a contact pressure in the Reynolds equation. Figure 2 shows the schema of the simulation model.

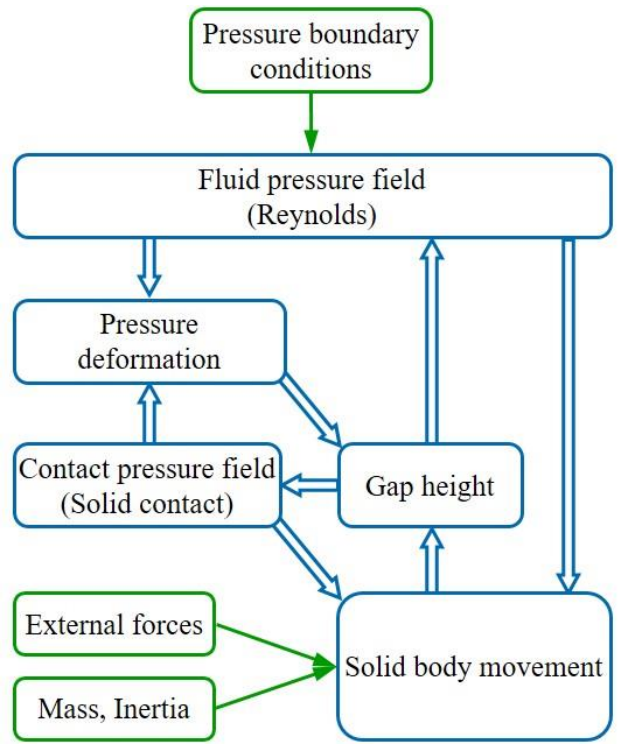

Figure 2: Schema of simulation model 


\section{MINIMAL GAP HEIGHT}

For the validation of the simulation's results, a test rig was developed at ifas and is described in detail in [7]. The valve plate is installed to a hydrostatic measure of the friction torque with a force sensor. Radial displacement sensors measure the cylinder block movement while an axial sensor measures the gap height between valve plate and cylinder block. With these data, the movement of the cylinder block can be calculated. Figure 3 side view of the test configuration.

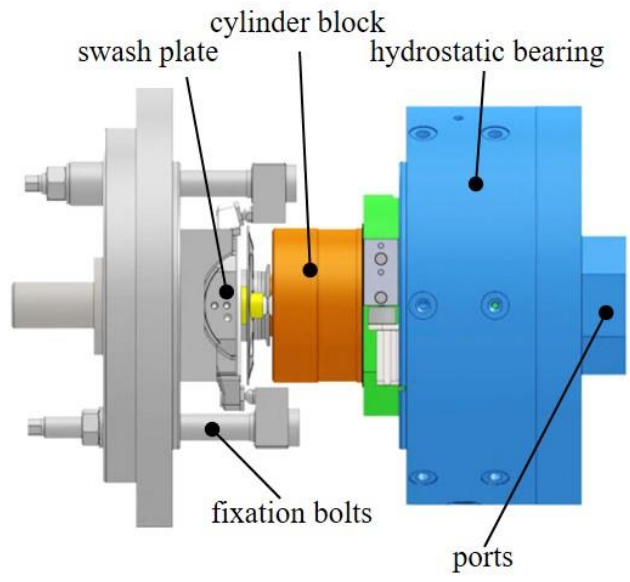

Figure 3: Test rig configuration

The test pump is a commercial pump with nine pistons and a displacement of $140 \mathrm{~cm}^{3}$. For the comparison of the experimental results with the simulated ones, the external forces and torques of the test pump were identified and implemented in the simulation tool.

In the simulation model Newton's law is used to calculate the cylinder block's movement. All external forces (mainly defined by the pressure within the cylinders), the fluid film forces (resulting from the pressure field calculated by the Reynolds equation) and the forces resulting from solid contact are summarized. Therefore, the gap height calculation represents the implementation of a fluid-structure interaction. [8]

To transfer the calculated movement of the cylinder block to the surface, two points are used. These two points lie on the main rotational axis of the cylinder block. The position of the two points are projected on a two dimensional coordinate system. Figure 4 shows this method and the two points, which are used for the simulation. The cylinder block's sphere center (C) is given by the spherical surface. The spline shaft center (S) lies on the main rotational axis of the cylinder block.

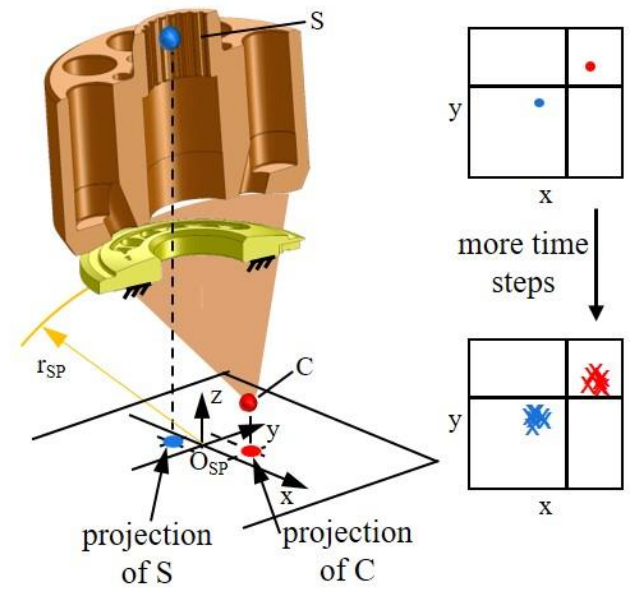

Figure 4: Projection of the cylinder block's movement

The gap height in axial piston machines is equal to the distance between the surfaces of the cylinder block and valve plate. The movement of the cylinder block defines the distance between the surfaces when assuming a stationary valve plate. For the investigation of the gap height distribution, the full movement in all degrees of freedom has to be considered. The location of the minimum and maximum gap height are of great importance for the understanding of friction, wear and contact pressure within the contact. Both, experimental results and those from the simulation show that the cylinder block performs a sliding movement over the valve plate's surface and tilts to the high pressure side. Figure 5 shows the simulation of pressure and gap height distribution for the two most relevant scenarios, in which five or four pistons are pressurized with high pressure. Other studies also show this effect. [9] Due to the tilt angle, the minimum gap height lies on the high pressure side between $130^{\circ}$ and $150^{\circ}$. The direction of rotation (DOR) of the cylinder block is clockwise. 

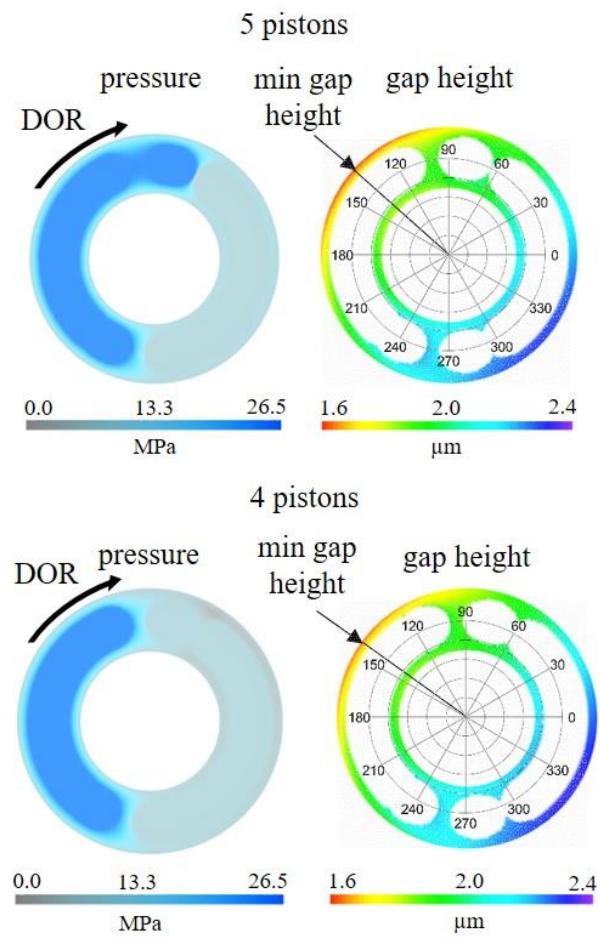

Figure 5: Minimum gap height position [8]

The measurement results of the experimental investigation are displayed in Figure 6. It shows the distribution frequency of the minimum gap height. The size of the red highlighted areas represents the occurrence frequency of the minimum gap height at the particular angular position for one revolution.

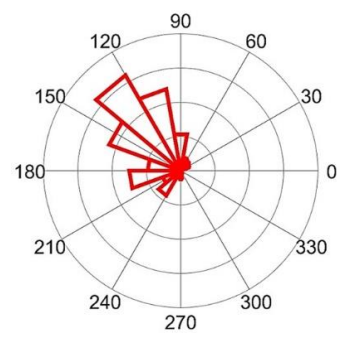

Figure 6: Frequency of minimum gap height [6]

The range $90^{\circ}-240^{\circ}$ is much higher as those from the simulation, but on average the minimum gap height is located at $130^{\circ}$.

There are not only disadvantages coming from this preferred position of the cylinder block. The load situation is highly inconstant due to the changing number of pistons on the high and the low pressure side. For the same reason the number of cylinders filled with fluid is also changing. Due to this fact, the cylinder block is very imbalanced. The first advantage of the preferred position of the cylinder block and its rapid movement towards this position is that it probably improves the smooth running of the axial piston machine by reducing the imbalance. The second advantage of the tilted cylinder block is lower leakage on the high pressure side. With the gap width $b$, the gap height $h$, the gap length $l$, the dynamic viscosity $\eta$ and the pressure difference $\Delta p$, the volume flow $Q$ through a small gap results from Equation 1 [2].

$Q=\frac{b \cdot h^{3}}{12 \cdot \eta \cdot l} \cdot \Delta p$

This equation shows the high influence of the gap height on the leakage and therefore on the volumetric efficiency of the machine. Because of the much higher pressure difference between the high pressure side and the housing pressure in comparison to the pressure difference on the low pressure side, there is a positive effect of the tilting.

These two advantages are countered by various disadvantages, which will be examined in further detail below. The tilting of the cylinder block reduces the already low gap height between valve plate and cylinder block. This increases the risk that the gap height becomes smaller than critical gap height and solid friction occurs. The resulting wear reduces the lifetime and efficiency of the axial piston machine or, in the worst case, can lead to immediate failure. In addition, the reduced gap height increases the fluid flow velocity as well as the shear rates. Due to this, the fluid load increases. The previously explained positive effect that the leakage decreases also includes a disadvantage. The reduced volume flow over the sealing gap reduces the heat dissipation. Therefore, in addition to the danger of solid friction a danger of local temperature hotspots exists. This effect is also described in $[10,11]$. Local high temperature ranges also limit the selection of possible alloys and coatings for the substitution of lead. Due to the risk of solid friction, it is not possible to use a hard/hard pairing in this tribological contact. Therefore, this paper presents a simulation study for the development of concepts to reduce the tilting of the cylinder block. 


\section{CONCEPT PRE-STUDY}

For the reduction of the cylinder block's tilt angle the torque balance has to be influenced by additional created torques. Two basic concepts can be used for it. The first concept is to add one or more forces in $\mathrm{z}$ direction. The second is to add those forces in radial direction. These concepts can be extended by the possibility that these forces are stationary or synchronized with the movement of the cylinder block. This allows a static torque to be created to reduce the tilting more or less constantly. On the other hand, a dynamic torque can be created, which imposes an additional imbalance on the cylinder block. This could avoid or at least reduce a fixed temperature hotspot. In this simulation study, these four concepts are considered separately to investigate the influence on the main parameters. The parameter variation and the results of the study are presented and discussed below. The pump geometry used in this simulation is taken from the test pump. Figure 7 shows the used cylinder block and valve plate. The geometrical data can be found in Table 1.
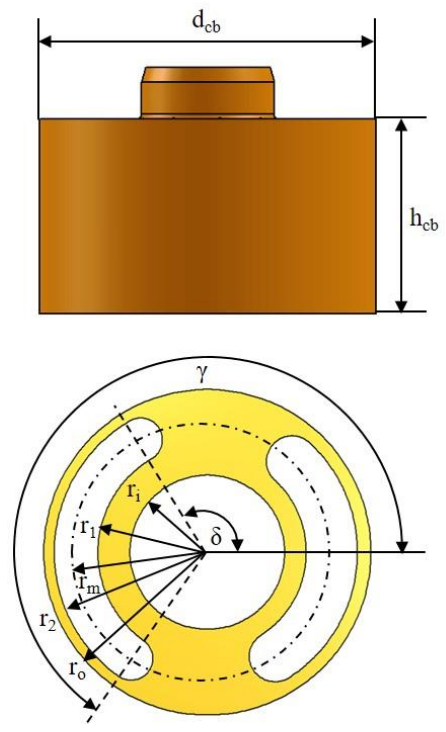

Figure 7: Cylinder block and valve plate
Table 1: Geometrical data

\begin{tabular}{cc}
\hline Parameter & Value \\
\hline $\mathrm{d}_{\mathrm{cb}}$ & $97.2 \mathrm{~mm}$ \\
$\mathrm{~h}_{\mathrm{cb}}$ & $80 \mathrm{~mm}$ \\
$\mathrm{r}_{1}$ & $29.45 \mathrm{~mm}$ \\
$\mathrm{r}_{2}$ & $44.55 \mathrm{~mm}$ \\
$\mathrm{r}_{\mathrm{i}}$ & $23 \mathrm{~mm}$ \\
$\mathrm{r}_{\mathrm{m}}$ & $37 \mathrm{~mm}$ \\
$\mathrm{r}_{\mathrm{o}}$ & $48.6 \mathrm{~mm}$ \\
$\gamma$ & $225^{\circ}$ \\
$\delta$ & $120^{\circ}$ \\
\hline
\end{tabular}

\subsection{Static force $z$-directional}

The first option to create a counter torque against the tilting of the cylinder block is to add a force in positive $\mathrm{z}$ direction and to place this force around the area of minimum gap height. For the investigation of this concept, the three main parameters are the value of the force and the position described by the angle and radius. The force is variated in the range from $625 \mathrm{~N}$ to $2500 \mathrm{~N}$. These values are equivalent to a pressurized surface from $25 \mathrm{~mm}^{2}$ to $100 \mathrm{~mm}^{2}$ at $25 \mathrm{MPa}$ on high pressure side. The angle is varied around the area of the minimum gap height between $120^{\circ}$ to $150^{\circ}$ while radius is varied in the range from $29.45 \mathrm{~mm}$ to $44.55 \mathrm{~mm}$ due to the high pressure kidney's geometry of the valve plate. Table 2 shows the parameter variation.

Table 2: Parameter variation

\begin{tabular}{cccc}
\hline $\begin{array}{c}\text { Fore } \\
{[\mathrm{N}]}\end{array}$ & $\begin{array}{c}\text { Eq. surface } \\
(25 \mathrm{MPa}) \\
{\left[\mathrm{mm}^{2}\right]}\end{array}$ & $\begin{array}{c}\text { Angle } \\
{\left[{ }^{\circ}\right]}\end{array}$ & $\begin{array}{c}\text { Radius } \\
{[\mathrm{mm}]}\end{array}$ \\
625 & 25 & 120 & 29.45 \\
1250 & 50 & 135 & 37 \\
1875 & 75 & 150 & 44.55 \\
2500 & 100 & & \\
\hline
\end{tabular}

24 configurations have been simulated. The relative angle change of the tilting is used here as a comparative value. The tilting can be calculated with the gap height difference and the cylinder block's diameter by the following equation.

$\alpha=\sin ^{-1} \frac{\Delta h}{d_{C B} / 2}$ 
The relative angle change $\alpha_{\text {rel }}$ can be calculated with Equation 3. $\alpha_{\text {new }}$ is the tilting with the additional forces while $\alpha_{\text {previous }}$ is the tilting in the basic configuration.

$\alpha_{\text {rel }}[\%]=\left(\frac{\alpha_{\text {new }}}{\alpha_{\text {previous }}}-1\right) \cdot 100 \%$

Figure 8 shows the relative change of the tilt angle for the parameter variations. An additional force in negative $\mathrm{z}$-direction with the same value was added, so only the torque works against tilting and the cylinder block is not lifted.

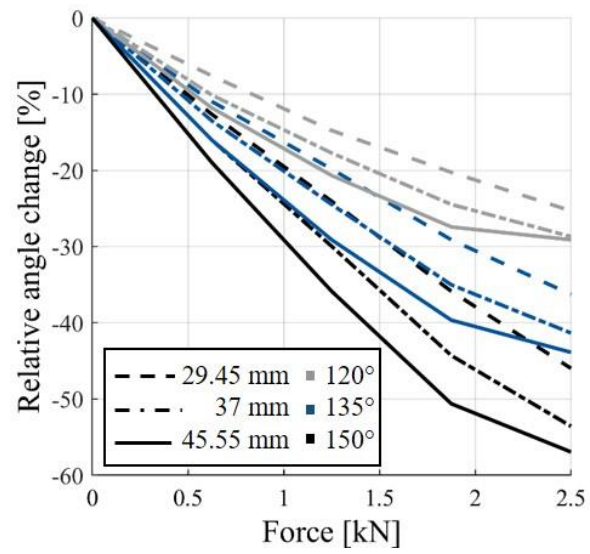

Figure 8: Relative angle change for static force in $\mathrm{z}$ direction

The simulation results show a major effect against the tilting for this concept. Even through the greatest effect is for the forces with an angle of $150^{\circ}$, the minimum gap height is at angle of $130^{\circ}$.

\subsection{Dynamic force $z$-directional}

By synchronising one or more additional added forces with the rotation of the cylinder block an additional imbalance results. The number of the added forces determines the frequency of this imbalance. These forces can be realized by pressurized surfaces on the cylinder block, which has an additional positive effect. The value of these forces depends on the rotational angle. The high pressure results in a high force and with it a high torque against the minimum gap height and tilt angle. The added surface has nearly no influence when it is not on the high pressure side. In this concept, the value of the added forces is varied as well as the radius. The parameter variation is concluded in Table 3.

Table 3: Parameter variation

\begin{tabular}{ccc}
\hline $\begin{array}{c}\text { Force } \\
{[\mathrm{N}]}\end{array}$ & $\begin{array}{c}\text { Eq. surface }(25 \mathrm{MPa}) \\
{\left[\mathrm{mm}^{2}\right]}\end{array}$ & $\begin{array}{c}\text { Radius } \\
{[\mathrm{mm}]}\end{array}$ \\
250 & 10 & 29.45 \\
500 & 20 & 37 \\
750 & 30 & 44.55 \\
1000 & 40 & \\
1250 & 50 & \\
\hline
\end{tabular}

There are 15 configurations resulting from this parameter variation. The relative change of gap height is used here as a comparative value. Because the added force is not constant, no counterforce was implemented. Due to this, the force lifts up the cylinder block while the resulting moment works against the tilting. Both effects influence the gap height. The relative change of gap height $h_{r e l}$ results from Equation 4. $h_{\text {new }}$ is the gap height with the additional forces while $h_{\text {previous }}$ is the gap height in the basic configuration.

$h_{\text {rel }}[\%]=\left(\frac{h_{\text {new }}}{h_{\text {previous }}}-1\right) \cdot 100 \%$

The simulation results are displayed in Figure 9.

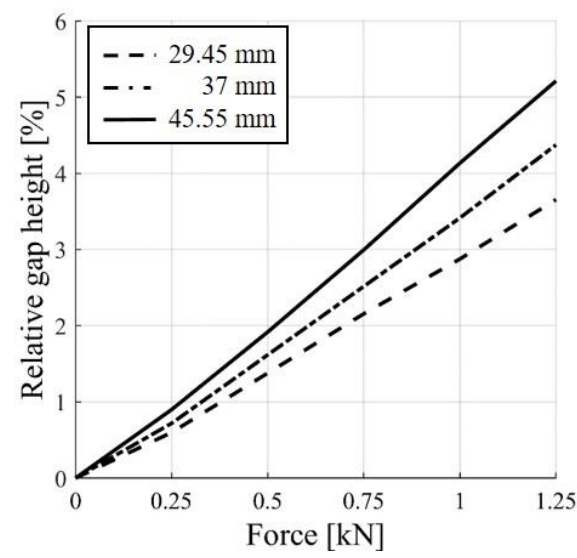

Figure 9: Relative change of gap height for dynamic force in $z$ direction 


\subsection{Static force radial direction}

Another possibility to create a torque against the tilting is to add forces in the radial direction which means the vector of the force lies in the $\mathrm{x}$ y-plane. Figure 10 illustrates this concept idea.
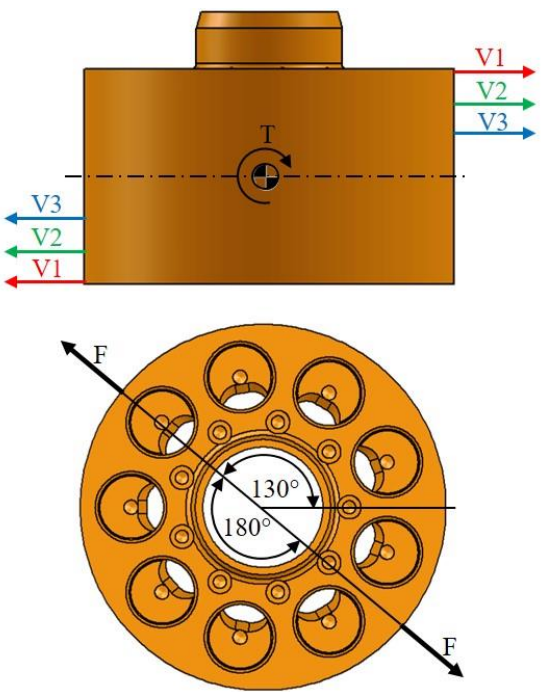

Figure 10: Concept illustration for additional forces in radial direction

A counter force with the same value is added to avoid eccentricity. The value of the force and three variations of the heights are varied. The relative angle change of the tilt angle is used here as a comparative value.

Figure 11 shows the simulation results for a simulation of the forces added at V1.

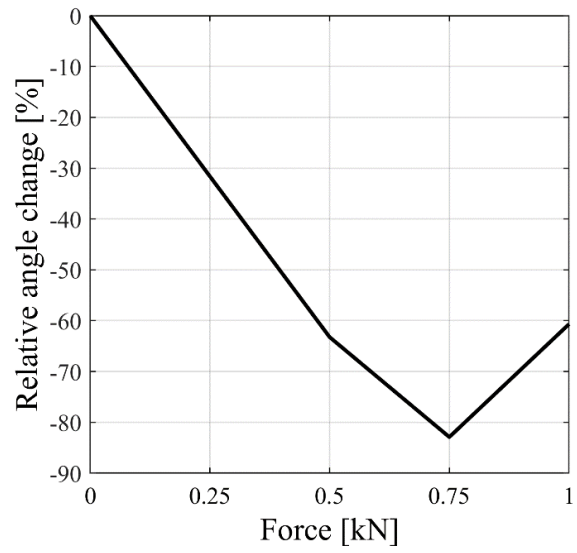

Figure 11: Relative angle change for static force in radial direction
The results show a reduction of more than $80 \%$ for forces of $750 \mathrm{~N}$. It is also evident that the cylinder block is tilting in another direction for forces of $1000 \mathrm{~N}$.

\subsection{Dynamic force radial direction}

One or more forces in radial direction can be added and synchronised to the rotational angle. The parameters are varied as is it was done in the simulation of the static force in radial-direction. Figure 12 shows the effect of this imbalance on the tilt angle.

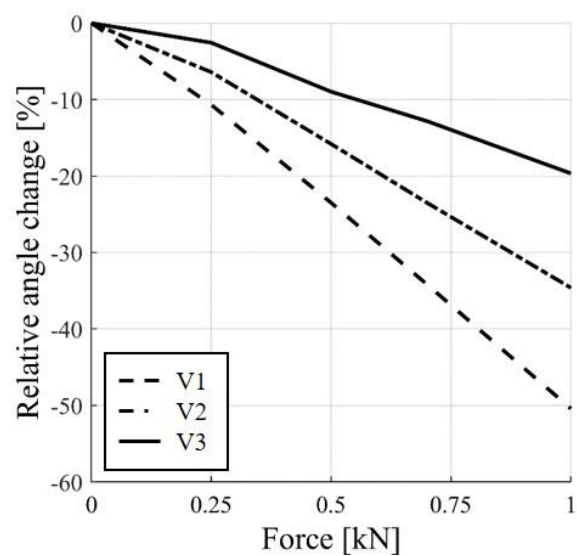

Figure 12: Relative angle change for dynamic force in radial direction

Due to the imbalance resulting from the additional forces, the relative angle change assumes positive and negative values. This concept even leads to a temporary reduction of the minimum gap height.

\subsection{Comparison}

Of the concepts presented against the tilting of the cylinder block, the static force in the z-direction in particular has great potential. The effect on the tilting angle is substantial even with relatively small forces. An additional pressure pocket in the high-pressure area of the valve plate makes this concept technically feasible. This concept and its potential have been investigated under consideration of the geometric limits. The investigation is described in the next chapter.

\section{STATIC PRESSURE FORCE}

From the previous explained concepts the realization of concept of the static force in 
$\mathrm{z}$-direction is presented and discussed in this chapter.

The realization of additional power in hydraulic machines can be achieved by additional pressurized surfaces. Haug [12], for example, added additional surfaces to control the degree of relief of tribological contacts. For the concept presented here, additional surfaces would have to be implemented in the sealing gaps of the valve plate's high pressure kidney. The position of these surfaces should be in the area of $150^{\circ}$ which is the most effective area. Figure $\mathbf{1 3}$ shows the geometry of the sealing gaps for the considered area.

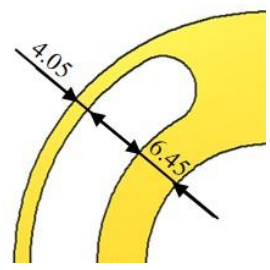

Figure 13: Sealing gap width

For the design of the sealing gap, it is recommended in [13] to choose the width depending on the length of cylinder block's kidney $(t)$ in the interval of $0.125 \ldots 0.175 \cdot t$. In the geometry considered here, $t$ corresponds to the diameter of the piston bore of $25 \mathrm{~mm}$. The minimum width according to this guideline is therefore $3.125 \mathrm{~mm}$. This results in a potential of $0.925 \mathrm{~mm}$ for the sealing gap to the housing and $3.325 \mathrm{~mm}$ for the one to the shaft. The maximum possible surface is $145.72 \mathrm{~mm}^{2}$. This results in a maximum force of $3.64 \mathrm{kN}$ by pressurizing it with the operating pressure of 250 bar. The surface 2 is $104.92 \mathrm{~mm}^{2}$ and the surface 1 is 40.8 $\mathrm{mm}^{2}$. The point of application of the resulting pressure force is at a radius of $33.67 \mathrm{~mm}$. Figure 14 shows the optimized geometry with maximum possible surface. It also shows a surface of $101.01 \mathrm{~mm}^{2}$ with a resulting force of $2.5 \mathrm{kN}$. This was the maximum force of the prestudy. The surface 2 is $60.21 \mathrm{~mm}^{2}$ and the surface 1 is $40.8 \mathrm{~mm}^{2}$. The point of application of the resulting pressure force is at a radius of $35.44 \mathrm{~mm}$. The sealing gap width is only reduced by $2 \mathrm{~mm}$.

Both optimizations were implemented in the simulation model. In the first simulation runs, the value of the counter force, so that the cylinder block is not lifting, had to be found iteratively.

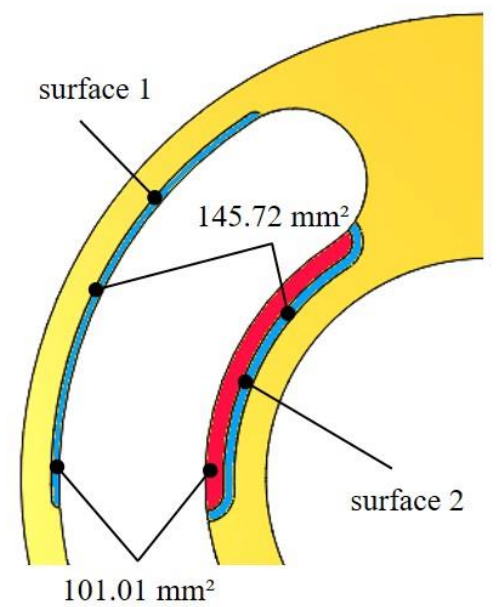

Figure 14: Additional pressure pockets

For the maximum surface, this additional force is $6 \mathrm{kN}$ while for the surface of $101.01 \mathrm{~mm}^{2}$ it is $5.5 \mathrm{kN}$. The simulation results show that the maximum possible surface reduces the tilt angle about $69.92 \%$ and the contact pressure in the area of minimum gap height about $38.93 \%$. The surface of $101.01 \mathrm{~mm}^{2}$ reduces the tilt angle about $56 \%$. In this case, the contact pressure is reduced about $37.69 \%$. These results show the high potential for the optimization of the tribological contact valve plate/cylinder block.

\section{CONCLUSION AND OUTLOOK}

The most widely used type of hydraulic displacement machines are axial piston machines. The tribological contact valve plate/cylinder block is one of three essential tribological contacts in such machines. Its optimization has a great influence on the efficiency of the whole unit. For the substitution of the commonly used leaded brass alloy to realize a hard/soft pairing in this contact the tilting of the cylinder block has to be reduced. In a research project at ifas a simulation model and a test ring has been built up. The results of simulation and experiments show that the cylinder block is tilting to the high pressure side. From this tilting a reduced gap height in the area of $130^{\circ}$ occurs. There, wear and heat dissipation according to solid friction and higher fluid velocity increase.

This paper presents the pre-study of four concepts for the reduction of the cylinder block's 
tilt angle. The reduction of the tilt angle was investigated by adding forces in z-direction and radial direction with various parameters. Dynamic forces in the same directions are added. The imbalance resulting from these forces reduces the tilting only for rotation angle range of high pressure kidney. All of these concepts have a good potential for the reduction of the cylinder block's tilting in a constant position. The realization of the static force in z-direction by additional pressure pocket at high pressure kidney of the valve plate has a very high potential. The simulation results show that a tilt angle reduction up to $69.92 \%$ is possible by adding the maximum possible surface of $145.72 \mathrm{~mm}^{2}$.

The next steps in the ongoing research project are to find the optimum geometry for this concept and its influence to leakage as well as power losses. Therefore, several simulation runs and prototype tests are needed for this iterative process. Possibilities for the realization of the other three concepts presented in this paper have to be developed.

\section{ACKNOWLEGEMENT}

This work was performed in the scope of the project "Increasing the efficiency of the cylinder block/valve plate contact in axial piston machines" (M41225/44-1), which is funded by the German Research Foundation (DFG). The authors would to thank the German Research Foundation for funding the project.

\section{NOMENCLATURE}

$\begin{array}{ll}b & \text { Gap width } \\ C & \text { Center point of cylinder blocks sphere } \\ C B & \text { Cylinder block } \\ D O R & \text { Direction of rotation } \\ d_{C B} & \text { Cylinder block's outer diameter } \\ F & \text { Force } \\ h & \text { Gap height } \\ h_{C B} & \text { Cylinder block's height } \\ h_{\text {min }} & \text { Minimum gap height } \\ h_{\text {new }} & \text { New minimum gap height } \\ h_{\text {rel }} & \text { Relative change of minimum gap height } \\ h_{\text {previous }} & \text { Previous minimum gap height } \\ \text { ifas } & \text { Institute for fluid power drives and systems } \\ l & \text { Gap length } \\ \Delta p & \text { Pressure difference } \\ Q & \text { Volume flow }\end{array}$

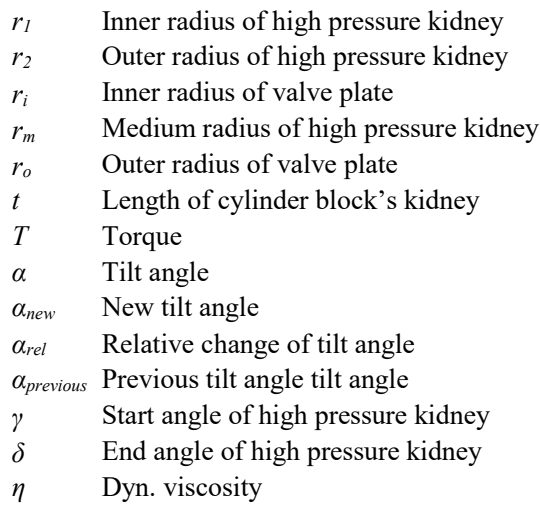

\section{REFERENCES}

[1] Jang, D.-S. (1997) Verlustanalyse an Axialkolbeneinheiten, Aachen, Germany, 1997

[2] Schmitz K., Murrenhoff H. (2018), Grundlagen der Fluidtechnik Teil 1: Hydraulik, Shaker Verlag, Aachen, 2018

[3] Table of restrited substances under REACH, European Chemicals Agency

[4] Paulus A. (2016) Tribolayer Formation on Bronze $\mathrm{Cu} \mathrm{Sn} 12 \mathrm{Ni} 2$ in the Tribological Contact between Cylinder and Control Plate in an Axial Piston Pump with Swashplate Design, 10th International Fluid Power Conference, Dresden, Germany, 2016

[5] Gels S. (2011), Einsatz konturierter und beschichteter Kolben-Buchse-Paare in Axialkolbenmaschinen in Schrägscheibenbauweise, Aachen, 2011

[6] Wegner S, Gels S., Murrenhoff H. (2014), Simulation of the tribological contact cylinder block/valve plate and influence of geometry and operation points on the friction torque in axal piston machines, The 9th International Fluid Power Conference, Aachen, Germany, 2014

[7] Wegner S., Gels S., Jang D.-S., Murrenhoff H. (2015), Experimental investigation of the cylinder block movement in an axial piston machine, ASME Symposium on Fluid Power and Motion Control, Bath, Great Britain, 2015

[8] Wegner S, Gels S., Murrenhoff H. (2016), Validation of the physical effect implementation in a simulation model for the cylinder block/valve plate contact supported by experimental investigations, 10th International Fluid Power Conference, Dresden, Germany, 2016 
[9] Achten P, Eggenkamp S. (2017), Barrel tipping in axial pumps and motors, 15th Scandinavian International Conference on Fluid Power, Linköping, Sweden, 2017

[10] Zecchi M., Mehdizadeh A., Ivantysynova M. (2013), A novel fluid structure interaction and thermal model to predict the cylinder block/valve plate interface performance in swash plate type axial piston machines, 13th Scandinavian International Conference on Fluid Power, Linköping, Sweden, 2013

[11] Ivantysyn R. (2017), An approach to visualize limiting factors in the cylinder block/valve plate gap in Axial Piston Pumps, ASME Symposium on Fluid Power and Motion Control, Bath, Great Britain, 2017

[12] Haug S., Geimer M. (2016), Optimierung von Axialkolbenmaschinen durch bedarfsangepasste Entlastung tribologischer Kontakte, 9. Kolloquium Mobilhydraulik, Karlsruhe, Germany, 2016

[13] Ivantysyn J., Ivantysynova M. (1993), Hydrostatische Pumpen und Motoren, 1. Auflage, Vogel, Würzburg, Germany, (1993) 